\title{
The Effect of Surgical Timing on the Outcomes of Pediatric Gartland Type III Supracondylar Humeral Fractures
}

\author{
(D) Cem Dinçay Büyükkurt, (D) Mustafa Yerli, (D) Süleyman Semih Dedeoğlu, (D) Yunus İmren, (D) Mustafa Çağlar Kır, (D) Ali Çağrı Tekin \\ University of Health Sciences Turkey, Prof. Dr. Cemil Taşçığlu City Hospital, Clinic of Orthopedics and Traumatology, Istanbul, Turkey
}

\section{Abstract}

Objective: In this study,we aimed to evaluate the effect of surgical treatment timing of Gartland extension type III humeral fractures on functional and cosmetic outcomes, in the pediatric age group and to compare them with literature.

Methods: Between November 2015 and October 2018, files of patients who were admitted to the emergency orthopedics department with Gartlantd extension type III supracondylar humeral fractures and who underwent surgery were investigated. Fifty cases under the age of 15 years were included in the study. These patients were divided into two groups (early and late groups) by examining time before surgery. At outpatient follow up, functional and cosmetic results were evaluated using Flynn criteria at the $12^{\text {th }}$ postoperative week.

Results: Fifty patients (58\% males and 42\% females) with an average age of 79.7 months (range $=15-164$ months) were included in the study. All of the patients had closed fractures. Surgical open reduction rate was $30 \%(n=15)$, with $20 \%(n=5)$ in the early group and $40 \%$ ( $n=10)$ in the late group. Patients were evaluated according to Flynn criteria at the $12^{\text {th }}$ week of outpatient follow up. In the early group, $92 \%$ ( $n=23$ ) and $8 \%(n=2)$ of patients had excellent and good cosmetic results, respectively; $64 \%(n=16), 28 \%(n=7), 4 \%(n=1)$, and $4 \%(n=1)$ had excellent, good, moderate, and poor functional results, respectively. When the outpatient clinic records of the late group patients were examined, $88 \%$ $(n=22)$ and $12 \%(n=3)$ had excellent and good cosmetic results, respctively, and $52 \%(n=13), 24 \%(n=3), 16 \%(n=4)$, and $8 \%(n=2)$ had excellent, good, moderate, and poor functional results, respectively. No significant difference was found between the two groups in terms of cosmetic and functional results $(p=0.641$ and $p=0.260$, respectively). However, it was observed that patients operated with a closed method had better functional outcome than those treated by open surgery $(p<0.001)$.

Conclusion: There was no significant difference between the early and late groups in terms of cosmetic and functional durations of the cases. However, we identified that early surgical treatment reduces operative time, C-arm fluoroscopy usage, hospitalization, and open surgery ratio. We propose that Gartland type III supracondylar humeral fractures should be treated with closed surgical methods within the first 12 hours considering the negative effect of open reduction on functional outcomes.

Keywords: Pediatric humeral fractures, supracondylar humeral fractures, timing of surgery, Flynn criteria

\section{INTRODUCTION}

The second most common fracture seen in the pediatric age group is the supracondylar humeral fracture. It constitutes approximately $50 \%$ of fractures around the elbow (1). These type of fractures are usually seen in the left upper extremity of boys aged 5-6 years (2). According to the Gartland classification, approximately $97-99 \%$ of these fractures are extension types. The injury mechanism is falling on an open hand when the elbow extended. In such fractures, the proximity of the neurovascular structures in the antecubital region to the fracture site increases the risk of direct injury and the risk of indirect damage due to pressure caused by the hematoma.

The aim of the treatment of pediatric supracondylar humeral fractures is to allow elbow movement as soon as possible. Treatment options range from closed reduction and plaster fixation to open surgery. According to Gartland classification, 
extension type III fractures should be treated surgically, because they are unstable with a risk of damage to neurovascular structures (3). In surgical practice, closed reduction and percutaneous pinning (CRPP) are the gold standard of surgical treatment. In cases where closed surgery is not enough to achieve anatomical reduction, switching to open surgery should be considered (4).

Complications of open or closed surgical treatment include pintrack infections, iatrogenic neurovascular injury, cubitus varus, hyperextension deformities (4).

In this study, we aimed to evaluate the effect of surgical treatment timing applied to Gartland extension type III humerus fractures in the pediatric age group on the functional and cosmetic outcomes determined using Flynn criteria and to compare them with literature.

\section{METHODS}

After approval from the local ethics committee (Okmeydanı Training and Research Hospital 06.02.2018-827), medical records of patients admitted to our emergency orthopedics department, with the diagnosis of Gartland type III supracondylar humeral fracture were obtained. Those who had undergone surgery were included in our study. Informed consent was obtained from all individual participants. Fifty cases under the age of 15 years were included in the study. Patients were divided into two groups: early group (those operated in the first 12 hours after trauma) and the late group (those operated after 12 hours). Both groups consisted of 25 patients.

The age, gender, fracture side, time to surgery, open or closed surgical treatment, use of C-arm floroscopy, incision site of the patients who underwent open reduction and hospitalization time were recorded.

Functional and cosmetic outcomes of the patients were determined using the Flynn criteria (5) (Table1) with face-to-face interview at a 12 weeks postsurgery outpatient clinic follow-up visit. Patients were followed up with $\mathrm{k}$-wire dressings, withdrawal of the wires based on radiological fracture healing findings, and the duration was recorded. Early complications such as pin tract or wound infection were investigated.

Inclusion criteria;

- Patients under 15 years,

- Gartland type III supracondylar humeral fractures,

- Surgically treated patients,
- Available hospitalization and outpatient clinic records.

Exclusion criteria;

- Open fractures,

- Patients with second fractures of the same extremity,

- Fractures with neurovascular deficit were not included in the study.

\section{Statistical Analysis}

SPSS (Statistical Package for Social Sciences) 21.0 and Microsoft Office Excel 2016 programs were used for statistical analysis. Shapiro-Wilk test was used to determine whether the study findings were in normal distribution. Comparisons between groups was done using independent t-test or analysis of variance. The Mann-Whitney U test was used for the non-parametric data. All statistical tests were two-sided and statistical significance was set at $p=0.05$. The results were analyzed on a $95 \%$ confidence interval basis.

\section{RESULTS}

There were 29 males (58\%) and 21 females (42\%) in the study. The mean age was $79.7 \pm 43.6$ months (range $=15-164$ months). Sixteen of the cases were right sided fractures. No statistically significant difference was found between the two groups as regards gender distribution, age, and fracture sides (Table 2).

All patients received premedication by anesthesists under emergency conditions before operation. Patients in the early group were operated within the first 12 hours and the mean time was $7.08 \pm 1.8$ hours. Patients in the late group were operated after at least 12 hours of admission and the mean time was recorded as $21.8 \pm 4.5$ hours. The mean postoperative duration of hospitalization was $1.8 \pm 0.4$ days in the early group and it was $2.7 \pm 1.3$ days in the late group. The hospitalization period of the patients who were operated in the early period

\begin{tabular}{|l|l|l|}
\hline \multicolumn{2}{|l|}{ Table 1. Flynn criteria (5) } \\
\hline & Cosmetic & Functional \\
\cline { 2 - 3 } & $\begin{array}{l}\text { Carrying angle } \\
\text { loss ( })\end{array}$ & $\begin{array}{l}\text { Total ROM of elbow } \\
\text { loss ( })\end{array}$ \\
\hline Satisfactory & $0-5$ & $0-5$ \\
\hline Excellent & $6-10$ & $6-10$ \\
\hline Good & $11-15$ & $11-15$ \\
\hline Fair & $>15$ & $>15$ \\
\hline Unsatisfactory & \multicolumn{2}{|l}{} \\
\hline Poor & \multicolumn{2}{|l}{} \\
\hline ROM: Range of motion
\end{tabular}


was statistically significantly shorter than those in the late group $(p=0.002)$ (Table 2).

All patients were operated by the same surgical team. The mean duration of surgery was $36.4 \pm 14.4$ minutes in the early group and $58.2 \pm 23.1$ minutes in the late group. When the C-arm fluoroscopy usage times during the operation were examined, it was $10.9 \pm 1.8$ seconds in the early group and $22.3 \pm 2.2$ seconds in the late group. Operation and C-arm fluoroscopy usage times were significantly lower in the early group $(p<0.001)$ (Table 2$)$.

Open surgical reduction ratio was $30 \%(n=15)$ in all patients. Five of these patients were in the early group, 3 were operated by lateral incision, and 2 were operated by lateral and medial approaches. The remaining 10 patients were part of the late group. Four of them were operated by lateral and the others by lateral and medial approaches. There was no statistically significant difference between the groups in terms of surgical reduction method $(p=0.127)$. However, patients treated by closed surgery had significantly lower age, hospitalization, and operation times than those treated by open surgery $(p<0.001)$ (Table 3). In addition, it was observed that patients operated with closed method had better functional outcome than those treated by open surgery $(p<0.001)$ (Figure 1$)$. None of the patients had neurovascular complications in the early

\begin{tabular}{|l|l|l|l|l|}
\hline \multicolumn{2}{|l|}{ Table 2. Demographic data of patients } \\
\hline & $\begin{array}{l}\text { Early } \\
\text { group }\end{array}$ & $\begin{array}{l}\text { Late } \\
\text { group }\end{array}$ & $\begin{array}{l}\mathbf{p} \\
\text { values }\end{array}$ & $\begin{array}{l}1-\beta \\
\text { values }\end{array}$ \\
\hline Gender & & & $0.77^{*}$ & \\
\hline $\begin{array}{l}\text { Female } \\
\text { Male }\end{array}$ & $\begin{array}{l}10(20 \%) \\
15(30 \%)\end{array}$ & $\begin{array}{l}11(22 \%) \\
14(28 \%)\end{array}$ & & \\
\hline Age (months) & $68 \pm 28.8$ & $90 \pm 53$ & $0.08 * *$ & \\
\hline $\begin{array}{l}\text { Side } \\
\text { Right } \\
\text { Left }\end{array}$ & $9(18 \%)$ \\
\hline $\begin{array}{l}\text { Admission peirod } \\
\text { (day) }\end{array}$ & $16(32 \%)$ & $\begin{array}{l}7(14 \%) \\
18(36 \%)\end{array}$ & $0.54 * *$ & \\
\hline Surgery time (minute) & $36.4 \pm 14.4$ & $58.2 \pm 23.1$ & $<0.001$ & $98 \%$ \\
\hline $\begin{array}{l}\text { C-arm fluoroscopy } \\
\text { usage time (second) }\end{array}$ & $10.9 \pm 1.8$ & $22.3 \pm 2.2$ & $<0.001$ & $99 \%$ \\
\hline *Mann-Whitney U test, **Student t-test & $2.7 \pm 1.3$ & 0.002 & $91 \%$ \\
\hline
\end{tabular}

Table 3. Comparison of patients between surgical reduction groups

\begin{tabular}{|l|l|l|l|l|}
\hline & $\begin{array}{l}\text { Closed } \\
\text { surgery }\end{array}$ & $\begin{array}{l}\text { Open } \\
\text { surgery }\end{array}$ & $\begin{array}{l}\mathbf{p} \\
\text { values }\end{array}$ & $\begin{array}{l}\mathbf{1 - \beta} \\
\text { values }\end{array}$ \\
\hline Age (months) & $68 \pm 39.8$ & $109 \pm 36.8$ & $<0.001$ & $97 \%$ \\
\hline Admission peirod (day) & $1.9 \pm 0.5$ & $3 \pm 1.6$ & $<0.001$ & $91 \%$ \\
\hline Surgery time (min) & $40 \pm 12.1$ & $63 \pm 10.6$ & $<0.001$ & $99 \%$ \\
\hline
\end{tabular}

postoperative period. The mean duration of pin removal was $7.1 \pm 0.9$ weeks in the early group and $6.9 \pm 0.8$ weeks in the late group. No statistically significant difference was observed between both groups in terms of pin removal times ( $p=0.777$ ). In the outpatient follow up, only one patient had superficial pin-track infection and was treated with oral antibiotherapy.

Patients were evaluated according to Flynn criteria at the $12^{\text {th }}$ week of outpatient follow up. In the early group, 92\% $(n=23)$ and $8 \%(n=2)$ of patients had excellent and good cosmetic results, respectively; $64 \%(n=16), 28 \%(n=7), 4 \%(n=1)$, and $4 \%(n=1)$ had excellent, good, moderate, and poor functional results, respectively. When the outpatient clinic records of the late group patients were examined, $88 \%(n=22)$ and $12 \%(n=3)$ had excellent and good cosmetic results, respctively, and 52\% $(n=13), 24 \%$ $(n=3), 16 \%(n=4)$, and $8 \%(n=2)$ had excellent, good, moderate, and poor functional results, respectively. No significant difference was found between the two groups in terms of cosmetic and functional results ( $p=0.641$ and $p=0.260$, respectively).

\section{DISCUSSION}

Surgical treatment is the preferred treatment for Gartland extension type III supracondylar fractures, in order to provide normal function and to prevent deformity (1-3). CRPP is the gold standard of surgical treatment. In cases where closed surgery is not enough to achieve adequate anatomical reduction and stable fixation, switching to open surgery should be considered (6). All the 50 patients included in the study had Gartland extension type III supracondylar humeral fractures and were treated and followed up by the same surgical team.

In literature, the rate of open presentation of humeral distal pole fractures varies between $5 \%$ and $10 \%$ (2). All patients in our series presented to the emergency department with closed fractures.

Supracondylar humeral fractures are often seen in children under 10 years of age. The mean age of the patients in our study was 6.6 years (range $=1-13$ years). Males (58\%) and left upper extremity (68\%) were dominant in accordance with literature (2).

When supracondylar humeral fractures are treated with CRPP, hospitalization periods are shorter than with open surgery, and there is a decrease in the incidence of complications such as infection and joint stiffness. However, in patients with no satisfactory results after closed reduction due to high fracture displacement, swelling, edema, and soft tissue damage, open precedures should be considered (7-9). In our study, patients who were operated upon late or underwent open surgery had a longer hospital stay than other patients. Although there 
are publications reporting $73 \%$ of open surgery rate, this rate is between $10 \%$ to $15 \%$ on average, in literature (9-12). In our series, open reduction was performed in 15 cases (30\%), higher than that in literature. Despite the absence of significant data, we thought that this high rate was due to delayed transfer of patients from the primary and secondary health care facilities to the upper center where definitive treatment was done. This delay causes an increase in soft tissue swelling and edema, which prevents effective closed surgery.

Early surgical treatment affects both cosmetic and functional results and reduces complication rates (13). There was no significant difference between the groups in terms of cosmetic and functional results. However, when the patients were divided into groups in terms of surgical method, functional results of the patients treated with open surgery were significantly worse than closed surgical group.

Supracondylar humeral fractures are one of the orthopedic emergencies (2). Prolonged preoperative waiting times are effective in increasing the regional soft tissue swelling and thus, reduce the chance of closed reduction. There is no consensus in literature on the effect of prolonged waiting time on complications and outcomes. In some studies, the results obtained from open or closed surgical treatment within 12 hours are not different from the ones operated after 12 hours $(14,15)$. Conversely, there are publications that suggest that early surgery facilitates surgical fracture reduction (16). In our study, no difference was found between the patients who underwent surgery in the early and the late groups, in terms of cosmetic and functional results.

According to Flynn criteria, Fowles and Kassab (17) reported 87.5\%, Davis et al. (18) 80\% and Sharma et al. (19) achieved 90\% satisfactory results. We found a rate of $94 \%$, which is consistent with that found in literature.

One of the most common early complications of open or closed surgical treatment of supracondylar humeral fracture is pin tract infection. In literature, the frequency of pin tract infection varies and is found between $2.5 \%$ and $35.6 \%(20,21)$. Acute nerve injury data have also been reported between $10 \%$ and $20 \%$ (18). No acute nerve injury was observed in our study, and only 1 patient (2\%) developed superficial pin tract infection, treated with oral antibiotherapy.

\section{CONCLUSION}

In conclusion, unstable supracondylar humeral fractures are common in childhood, and require urgent surgical intervention.
The main purpose is to provide early anatomic reduction and stabilization and achieve satisfactory functional and cosmetic results subsequently.

There was no significant difference observed in terms of waiting time for surgery and cosmetic and functional outcomes of patients. However, we observed that early surgical treatment reduces operative time, C-arm fluoroscopy usage, hospital stay, and open surgery ratio. We propose that Gartland type III supracondylar humeral fractures should be treated with closed surgical method within the first 12 hours considering the negative effect of open reduction on functional outcomes.

\section{Ethics}

Ethics Committee Approval: Okmeydanı Training and Research Hospital 06.02.2018-827.

Informed Consent: Informed consent was obtained from all individual participants.

Peer-review: Externally and internally peer-reviewed.

\section{Authorship Contributions}

Surgical and Medical Practices: C.D.B., M.Y., S.S.D., Y.I., M.Ç.K., A.C..T., Concept: C.D.B., M.Y., S.S.D., Y.I., M.C..K., A.Ç.T., Design: C.D.B., M.Y., S.S.D., Y.I., M.C..K., A.C..T., Data Collection or Processing: C.D.B., M.Y., S.S.D., Y.I., M.C..K., A.C..T., Analysis or Interpretation: C.D.B., M.Y., S.S.D., Y.I., M.C..K., A.C..T., Literature Search: C.D.B., M.Y., S.S.D., Y.I., M.C..K., A.C..T., Writing: C.D.B., M.Y., S.S.D., Y.I., M.Ç.K., A.Ç.T.

Conflict of Interest: No conflict of interest was declared by the authors.

Financial Disclosure: The authors declared that this study received no financial support.

\section{REFERENCES}

1. İnan M, Yücel B. Çocuklarda Humerus Suprakondiler Bölge Kırıkları. TOTBID 2008;7:104-11.

2. Beaty James H, Kasser James R. Rockwood ve Wilkins' Fractures in Children 7theditionWolters Kluwer Lippincott Williams \&Wilkins, 2009; Chapter 13-14: p. 475-532.

3. Gartland JJ. Management of supracondylarfractures of thehumerus in children. Surg Gynecol Obstet 1959;109:145-54.

4. Tripuraneni KR, Bosch PP, Schwend RM, Yaste JJ. Prospective, surgeonrandomize devaluation of crossed pins versus lateral pins for unstable supracondylar humerus fractures in children. J Pediatr Orthop B 2009;18:93-8

5. Flynn JC, Matthews JG, Benoit RL. Blind pinning of displaced supracondylar fractures of the humerus in children. Sixteen years' experience with long-term follow-up. J Bone Joint Surg Am 1974;56:26372. 
6. Omid R, Choi PD, Skaggs DL. Supracondylar humeral fractures in children. J Bone Joint Surg Am 2008;90:1121-32.

7. Kaewpornsawan K. Comparison between closed reduction with percutaneous pinning and open reduction with pinning in children with closed totally displaced supracondylar humeral fractures: a randomized controlled trial. J Pediatr Orthop B 2001;10:131-7.

8. Ozkoc G, Gonc U, Kayaalp A, Teker K, Peker TT. Displaced supracondylar humeral fractures in children: open reduction vs. closed reduction and pinning. Arch Orthop Trauma Surg 2004;124:547-51.

9. Lewine E, Kim JM, Miller PE, Waters PM, Mahan ST, Snder B, et al. Closed versus open supracondylar fractures of the humerus in children: a comparison of clinical and radiographic presentation and results. J Pediatr Orthop 2018;38:77-81.

10. Abbott MD, Abbott MD, Buchler L, Loder RT, Caltoum CB. Gartland type III supracondylar humerus fractures: outcome and complications as related to operative timing and pin configuration. J Child Orthop 2014;8:473-7.

11. Pesenti S, Ecalle A, Peltier E, Choufani E, Blondel B, Jouve JL, et al. Experience and volume are determinantive factors for operative management of supracondylar humeral fractures in children. J Shoulder Elbow Surg 2018;27:404-10.

12. Kzlay YO, Aktekin CN, Özsoy MH, Akşahin E, Sakaoğullar A, Pepe M, et al. Gartland Type 3 Supracondylar Humeral Fractures in Children: Which Open Reduction Approach Should Be Used After Failed Closed Reduction? J Orthop Trauma 2017;31:18-22.

13. Sharma A, Walia JP, Brar BS, Sethi S. Early results of displaced supracondylar fractures of humerus in children treated by closed reduction and percutaneous pinning. Indian J Orthop 2015;49:529-35.
14. Pullagura M, Odak S, Pratt R. Managing supracondylar fractures of the distal humerus in children in a district general hospital. Ann R Coll Surg Engl 2013;95:582-5.

15. Han QL, Wang YH, Liu F. Comparison of complications and results of early versus delayed surgery for Gartland type III supracondylar humeral fractures in pediatric patients. Orthop Surg [Internet] 2011;3:242-6.

16. Yildirim AO, Unal VS, Oken OF, Gulcek M, Ozsular M, Ucaner A. Timing of surgical treatment for type III supracondylar humerus fractures in pediatric patients. J Child Orthop 2009;3:265-9.

17. Fowles JV, Kassab MT. Displaced supracondylar fractures of the elbow in children. A report on the fixation of extension and flexion fractures by two lateral percutaneous pins. J Bone Joint Surg Br 1974;56B:490-500.

18. Davis RT, Gorczyca JT, Pugh K. Supracondylar humerus fractures in children. Comparison of operative treatment methods. Clin Orthop Relat Res 2000;376:49-55.

19. Sharma A, Kahal K, Sharma S. Transolecranon and lateral Kirschner wire fixation for displaced supracondylar humeral fracture in children. J Orthop Surg 2015;23:319-22.

20. Lu D, Wang T, Chen H, Sun LJ. Management of pin tract infection in pediatric supracondylar humerus fractures: a comparative study of three methods. Eur J Pediatr 2017;176:615-20.

21. Tomaszewski R, Wozowicz A, Wysocka-Wojakiewicz P. Analysis of Early Neurovascular Complications of Pediatric Supracondylar Humerus Fractures: A Long-Term Observation. Biomed Res Int 2017;2017:2803790. 